\title{
Mitigation of Residual Flux for High-Temperature Superconductor (HTS) Transformer by Controlled Switching of HTS Breaker Arc Model
}

\author{
A. Ullah, T.T. Lie, K. Gunawardane \\ Department of Electrical and Electronic Engineering \\ Auckland University of Technology (AUT) \\ Auckland, New Zealand.
}

\author{
N.K.C. Nair \\ Department of Electrical and Computer Engineering \\ The University of Auckland \\ Auckland, New Zealand
}

\begin{abstract}
AC circuit breaker's controlled switching is a popular method to reduce dielectric and thermal stresses during switching of transformers, transmission lines, reactor and shunt capacitors. The magnitude of inrush current often reaches five to nine times of rated magnetizing current and thus it affects the network stability. Particularly, it affects the superconductivity of HTS transformer. Moreover, a residual flux is developed in HTS transformer due to high inrush current. The amount of flux may increase to a very high value that has direct impact to have a very high transient inrush current. This paper presents inrush current mitigation phenomena in a single-phase HTS transformer by controlled switching of HTS breaker arc model. The inrush current phenomenon is modeled for a single-phase HTS transformer in this paper. The mitigation of inrush current is restrained to a lower level by the reclosing of a new type of arc model named HTS breaker arc model and the residual flux also minimized. The calculating method is established on the investigation of fast switching timing and characteristics of the HTS breaker arc model.
\end{abstract}

Index Terms - HTS, arc model, inrush current, residual flux.

\section{INTRODUCTION}

The physics of HTS has been extensively researched and used as commercial prototypes during the 21 st century. Recently, there has been interest emerging amongst researchers on the use of HTS for power system equipment developments. These remarkable developments of HTS application for power industry has introduced numerous prospective aspects with new pathway of research. This covers areas like research on $\mathrm{Bi}_{2} \mathrm{Sr}_{2} \mathrm{Ca}_{2} \mathrm{Cu}_{3} \mathrm{O}_{10+x}$ series HTS product development, HTS magnets and systems, methods, alongside large-scale manufacturing strategies and techniques. The companies like General Cable Superconductors Ltd., HTS-110 Ltd. etc. are supporting the comprehensive research for commercial rollout. Other institutes like Industrial Research Ltd. (IRL) and Robinson Research Institute [1] also have pivotal rule for the development of these technologies. The study of HTS cables, HTS transformers [2,3], HTS wind turbine generators and HTS Fault Current Limiter [4], HTS external rotor machine [5] have been developed and trialed. This paper on HTS circuit breaker (HTSCB)'s controlled switching effect on HTS transformer is therefore highly relevant and impactful in the context of additional development of HTS implementation pathway. The study in this paper is an ongoing research for the protection of $11 \mathrm{kV}$ HTS applications. For this study, transient results of HTS breaker arc model has developed earlier [6]. The prescribed arc model demonstrates significant advantage of very low Rate of Rise of Re-striking voltage [7]. The simulation data displayed an acceptable agreement for future implementation. The analysis of superconducting transformer's inrush current with residual flux density and the magnetizing current is calculated in this paper. The IEC 62271-302 describes that circuit breaker's closing time may increase from 0.1 to 1 millisecond (ms) as a result of aging effect. Hence, it is important to analyse viability of any circuit breakers to satisfy controlled switching requirements [8]. It is experienced that circuit breaker's impact to inrush current can be reduced from $800 \mathrm{~A}$ to less than $15 \mathrm{~A}$ by static correction of 1 $\mathrm{ms}$ in its operating time. [8]. Once the performance of HTS arc model will be analyzed successfully for distribution network, then it can be implemented in smart grid for systems protection or in SCADA/energy management system (EMS) central systems. Controlled switching of HTS arc model is proposed in this paper that act independently for a complex network. The smart grid itself is not accountable for the removal of faulted components. The task is still need to be performed by the protection system. Breaker arc model with controlled switching acts to protect the system during emergencies in an intelligent approach.

\section{LIMITATION OF USUAL BREAKER}

The HTS transformers are claimed to be very efficient which are developed to meet the mechanical reliability of insulation and windings system. The most common high temperature superconductors used for HTS transformers are $\mathrm{Bi}_{2} \mathrm{Sr}_{2} \mathrm{Ca}_{2} \mathrm{Cu}_{3} \mathrm{O}_{\mathrm{x}}(\mathrm{Bi}-2223), \mathrm{YBa}_{2} \mathrm{Cu}_{3} \mathrm{O}_{\mathrm{x}}(\mathrm{Y}-123$ or $\mathrm{YBCO})$ and $\mathrm{Bi}_{2} \mathrm{Sr}_{2} \mathrm{Ca}_{1} \mathrm{Cu}_{2} \mathrm{O}_{\mathrm{x}}$ (Bi-2212). Such products established superconducting actions at the temperature below 105, 90 and $80 \mathrm{~K}$ correspondingly and works nicely in cryogenic condition [6-7]. Several studies are performed to investigate the operation of HTS power transformers in real life [8-9]. The HTS transformer performs pretty well in distribution network from technical and economical aspects [10-11]. 
HTS transformer, HTS generator, HTS cables and HTS current lead has been extensively used so far in HTS application for power system industry. The typical breakers has some limitations for HTS applications. For example, for the HTS transformer the limitation of using typical circuit breakers are numerous:

- Contact resistance value variance of similar or different materials in terminal joint with breaker during fault.

- $\quad$ Effects of circuit breaker prestrike voltage.

- High residual flux and inrush current values that harms the superconductivity.

- Variance in mechanical closing time of the contacts.

The idea of HTS breaker grown from these limitations [6-7]. A superconductor breaker can brings the advantage of contact resistance with another superconductor equipment. A breaker with superconductivity feature can overcome the effect of prestriking effect as well in great deal as discussed in [7].

\section{CONTROLled SWITCHING OF HTS ARC MODEL}

\section{A. Different switching methods}

Typically, three different approaches are followed to mitigate magnetic inrush in any power transformers.

(i) The residual fluxes can be ignored by shutting at peak of voltage. The phenomena can overcome reasonable degree of inrush current.

(ii) By shutting the load side voltage while prospective flux is equal to residual flux. Residual flux is measured by integrating load side voltages.

(iii) By controlled switching of breaker. The Residual flux needs to be locked to its least probable degree during every cycle through controlled de-energization. The method needs to be accompanied by controlled energization of HTS transformer. To the extent that prospective flux needs to be identical to the residual flux.

Other than these three methods Pre-Insertion Resistors (PIR) has also been used to mitigate inrush currents for transformers. Methods (ii) or (iii) are well-known method in order for mitigating inrush to a extremely decreased level. On load side Method (i) and (ii) needs supplemental voltage measurements. Method (iii) is chosen for this experiment among three methods for its efficiency, simplicity, and uncomplicated practical application.

\section{B. Details of Controlled Switching of breaker}

The method is named as Controlled switching or Controlled Fault Interruption (CFI) method. The simulation is performed for $11 \mathrm{kV}$ HTS breaker arc model in order to examine the arc model ability to interrupt a fault with CFI method. The short circuit current $I_{s c}$ is line breaker current for a fault applied near HTS transformer line. There are some requirements need to follow for CFI method at fault condition in AC breakers [12]. The requirements for this system is described as: i. Finding the target current zero times having realistic precision (approx. $\pm 0.5 \mathrm{~ms}$ ) ii. Finding the 'focus' current zero time (starting from
0.5 cycle) iii. Recognized steady circuit breaker opening time iv. Recognized steady minimum arcing time. Among the no. $\mathrm{i}$ and ii are limitation for the control algorithm. Requirement no iii and iv are controlled from the characteristics of the HTSCB. Any substantial calculation response time limitations aren't considered in the modified CFI algorithm. As, this is really incomprehensive if CFI algorithm of HTS arc model needs a number of cycles to find the 'Focus' point. In CFI algorithm, the synchronizing control of arcing time is important in order to achieve a successful tripping of HTS arc model. The simplified flow chart of modified CFI process is shown in Figure. 1. If the CFI method fail to arrive at a feasible 'focus' point, then a decision must be taken. The decision based on minimal operating time and waiting time help to permit the control scheme and to seek a viable solution. Otherwise it will defer tripping of HTS arc model for minimal operating time.

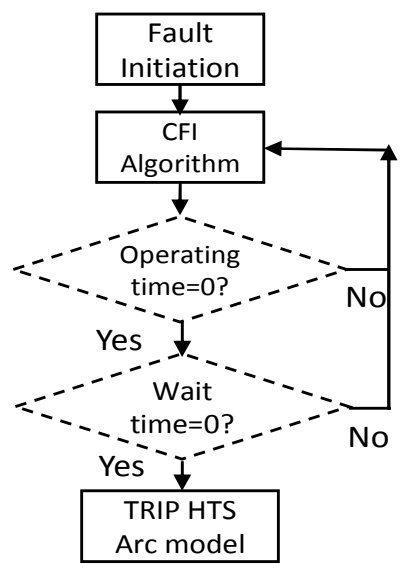

Figure 1: Simplified flow chart of CFI process with HTS breaker arc model

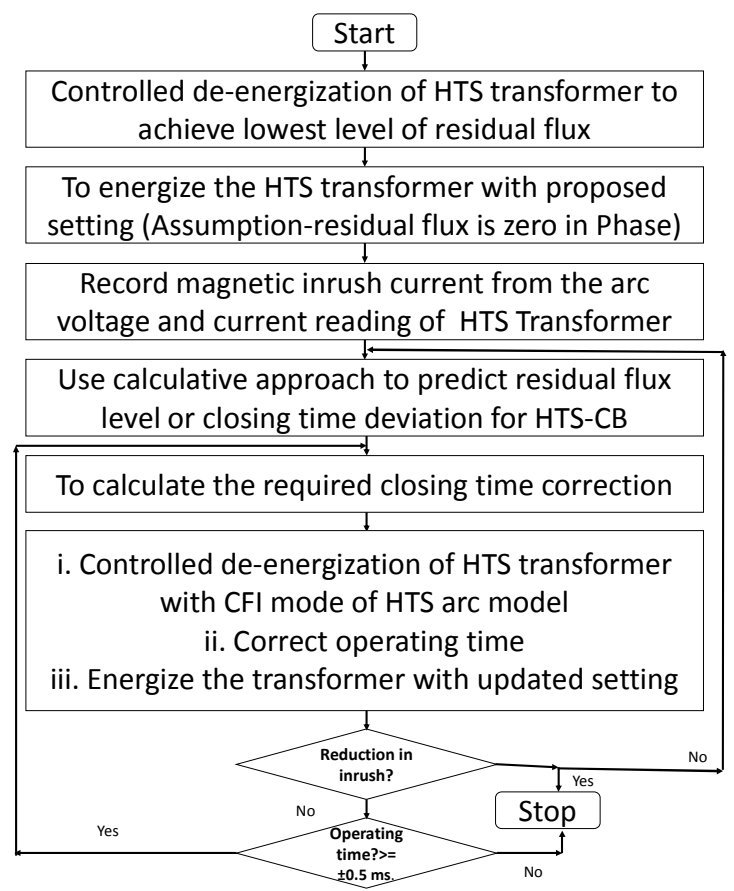

Figure 2: Modified Methodology of mitigating residual flux with CFI 
The proposed procedure is conveniently comprehended by block diagrams demonstrated in Figure 2. In very first step, residual fluxes in the phase is counted as zero. At the time of initial energization operation inrush current is recorded.

For next stages, the closing times for HTS breaker arc model is fixed by optimum value of $1 \mathrm{~ms}$ in order to reduce residual flux. An implementation of large correction value in the phases may result into misleading outcome. The high inrush current with faulty correction value would detrimentally affect HTS transformer's superconductivity. Afterward, transformer needs to be de-energized again in a controlled way. The phenomena will be accompanied by re-energization using adjusted updated settings. Inrush current can still be identified as increasing. In that case, entire method needs to be commence again and the operating time requires to be decreased more until ideal mitigation impact is obtained. During each energization attempt, controlled de-energization needs to perform earlier than the controlled energization procedure.

\section{Development of HTS Arc model}

A Browne's model for HTS application and its calculation of power system transients is performed using MATLAB Simulink. In this proposed model the HTS breaker mechanism is maintained with a time constant of first order. The setup is modelled as a frequency dependent model. When $11 \mathrm{kV}$ supply is applied, it results in a high current that exceeds the circuit breaker current rating and hence the breaker trips. The reset is then pressed, and the voltage is ramped up. The breaker trips beyond the circuit breaker current rating. This is the simple mechanism for the HTS arc model. A device block is used to switch the differential into physical measurement signals pressure, $P$ and temperature, $T$. In order to use the breaker especially for other HTS application, the MATLAB model assumes an ideal pressure and temperature sensor. The pressure and temperature are assessed across two ports of the HTS breaker arc model.
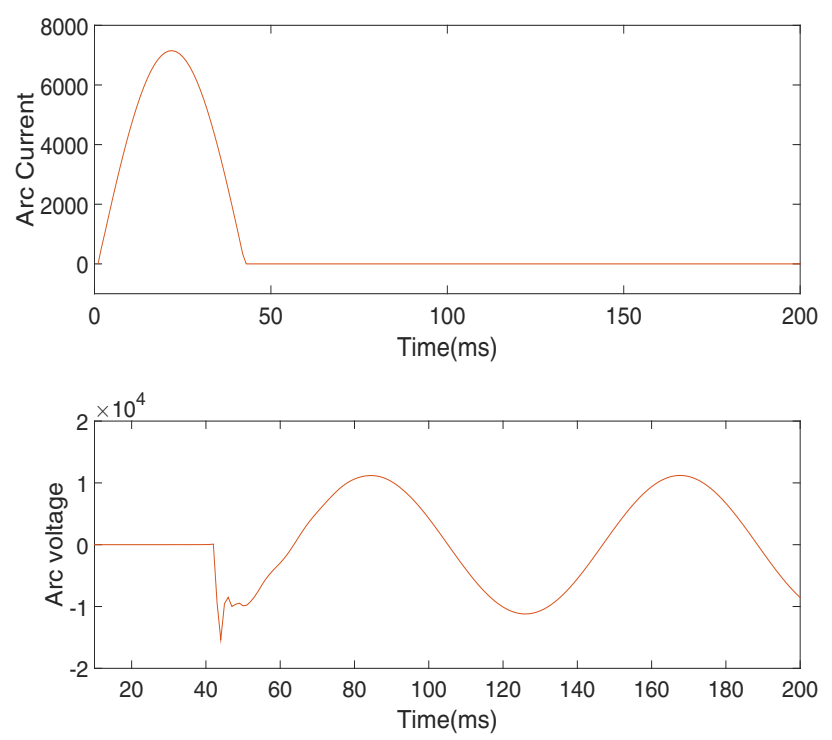

Figure 3: Arc voltage and current for HTS Arc model
In Figure 3, arc voltage and current for HTS arc model with Browne's model is shown. Three characteristics are: (i) The arc acts as a non-linear resistance. (ii) The power input for the arc channel recorded nearly zero value. (iii) Also the arc voltage also recorded constant for the high current period [6].

\section{Controlled switching of HTS arc model}

The energization of $11 \mathrm{kV}$ HTS transformers often results for high inrush currents. Consequently, it impose substantial thermal stresses on HTS transformers and associated circuit breakers. The controlled switching of AC circuit breakers is a popular method to overcome the inrush current. Though, there are some uncertainties in the measurement of circuit breaker's operating time [13]. CIGRE is noted to have good research works regarding the need of HVAC circuit breakers with controlled switching controller [14-15]. The method helps to reduce dielectric and thermal stresses during switching of shunt reactors and capacitors or transformers. Controlled switching features significant financial advantage along with several technical benefits. The performance of HTS breaker arc model has been used in this research to investigate its controlled switching. This is vital to get steady operating time of HTS circuit breaker or breaker arc model throughout the operations in order to attain similar amount of inrush current and residual flux level. Usually, most of the modern era breakers present outstanding operating time regularity within $\pm 0.5 \mathrm{~ms}$.

\section{INRUSH CURRENT ANALYSIS}

The calculation of inrush current analysis of the HTS arc model depends on its closing stage. The method of short circuit currents due to faults and inrush current flow through arc model is studied in this section. The inrush current is regarded as large value of the current peak magnitude. It is significant to investigate into a proper method for short circuit analysis. The form, value, degree and timeframe of the inrush current relies on numerous aspects like transformer structure, network topology, residual fluxes and circuit breakers characteristic etc. Inrush current currents may result for range of unwanted consequence in the system. Protective fuses, relays can be harmed. Harmonic resonance can damage windings or core of HTS transformer.

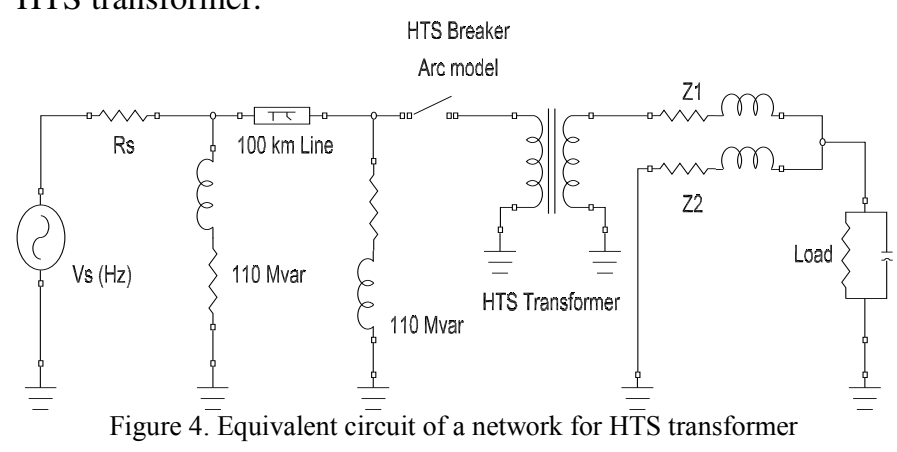

HTS transformer behaves as a simple inductance when it is switched on from primary section and secondary section is open. In Figure 4, equivalent circuit of a network for HTS transformer with HTS breaker arc model for inrush current analysis is shown. 


\section{A. Inrush current and magnetizing current analysis}

In normal condition, the flux reaches its highest value at $\pi / 2$ angle or at one-fourth cycle. The steady state value of flux also been measured. No flux should be associated to the HTS core before the supply is switched on. The flux value reaches to higher value depending on the switching of HTS arc model.

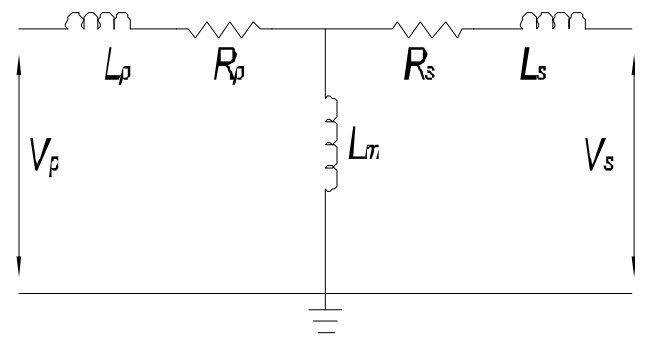

Figure 5: Equivalent circuit of HTS transformer

In Figure $5, R_{p}$ and $R_{s}$ are primary side resistance and secondary side resistance respectively. $L_{P}$ and $L_{S}$ represents the leakage reactance of primary and secondary side respectively. $L_{m}$ presents the inductance of the HTS core. While $V_{p}$ and $V_{s}$ are the terminal voltage of phase to ground from primary side and secondary side respectively. Primary side voltage is found from Figure 5 as:

$$
\begin{gathered}
V_{p}=V_{m} \sin (\omega t+\theta)=i_{\varphi} R_{p}+\frac{N_{1} d \emptyset_{L}}{d t} \\
=\frac{N_{1} \emptyset_{L} \cdot R_{p}}{L_{1}}+\frac{N_{1} d \emptyset_{L}}{d t}
\end{gathered}
$$

Where $N_{1}$ is number of turn, $\emptyset_{L}$ is core flux, $\theta$ is the voltagephase at $t=0, i_{\varphi}$ is magnetize current, $L_{1}$ is inductance in primary side .

$$
\emptyset_{t}=\left(\emptyset_{m} \cos \theta \pm \emptyset_{r}\right) e^{\frac{-R}{L}}-\emptyset_{m} \cos (\omega t+\theta)
$$

Where $\emptyset_{r}$ is residual flux and $\emptyset_{m}$ is maximum flux and. In Equation (2) At $\theta=\pi / 2$ it is found:

$$
\emptyset_{t}=\emptyset_{r} e^{\frac{-R t}{L_{m}}}+\emptyset_{m} \sin (\omega t)
$$

where residual flux magnitude, $\emptyset_{r}$ has some transient flux values and time constant $\tau=\frac{L_{1}}{R_{p}}$. The maximum of magnetizing current obtains as below:

$$
i_{\emptyset m}=\frac{\left(2 \emptyset_{m}+\emptyset_{r}-2.22 A_{i}\right)}{\mu_{0} A_{t}}
$$

where $A_{i}$ is area of core, $A_{t}$ is the area of the HTS core along winding and $\mu_{0}$ is air permeability. From equation (5) it is clear that $i_{\emptyset m}$ is directly proportional to the flux value corresponds to the magnetizing inrush current value of $\frac{B}{H}$ value which can minimize adjusting the value of phase angle of voltage at the time of switching.

\section{B. Inrush current effect on Residual flux}

Inrush current relies on the residual flux in HTS core. The transient current or Magnetizing inrush current occurs when transformer is energized. The inrush current value relies on few issues: (i) the voltage waveform point where the switches close (ii) the residual flux and (iii) hysteresis feature of the HTS core. As hysteresis feature is pre-set, therefore inrush current removal is considered from the viewpoint of residual flux mitigation. Inrush current and other transformer values can also be calculated when the residual flux is precisely calculated. In this section, the residual flux is analysed through transient values of HTS arc model arcing period. The estimated HTS transformer residual flux is found reduced eventually. Initial flux value of residual flux changes with the inrush current's maximum value. During short-current situation, air core reactance, $\mathrm{X}_{\mathrm{S}}$ restricts the code reactance which is described as follows:

$$
X_{s}=\frac{\mu_{0} \cdot A_{w} \cdot N^{2}}{h_{w}} \cdot 2 . \pi . f
$$

where $A_{w}$ is mean turn area, $N$ is number of turns and $h_{w}$ is excited winding height.

The angle, $\theta$ is represented as:

$$
\theta=K_{1} \cos ^{-1}\left(\frac{B_{r} \cdot B_{m p} \cdot B_{s}}{B_{m p}}\right)
$$

where $\mathrm{B}_{\mathrm{r}}$ is residual flux density, $\mathrm{B}_{\mathrm{mp}}$ is the maximum record of steady-state flux density and $\mathrm{B}_{\mathrm{s}}$ is saturation flux density in HTS core and $\mathrm{K}_{1}$ is correction factor.

The inrush current peak, $i_{\text {omax }}$, for the first cycle is described as:

$$
i_{0 \max }=\frac{\sqrt{2} \cdot K_{2} \cdot V}{X_{s}}(1-\cos \theta)
$$

where $K_{2}$ is the correction factor and $V$ is the applied voltage's rms value. [17].

\section{RESIDUAL FLUX CALCULATION}

Residual flux of HTS transformer relies on three issues: (i) the winding connection (ii) the structure of HTS transformer and (iii) power factor angle. As power factor angle is a changing value, the result should observe before switching off the HTS transformer.

As per the law of Faraday, core flux is acquired through the integration of induction voltage. The HTS breaker contacts are assumed to be separated when the transformer opens. The arc is found generated between the contacts [7]. In HTS breaker the arc blows out in cryogenic chamber till the current becomes zero. Subsequently, the current will turn to zero completely [6].

Primary voltage side's blow out angle is considered as identical to the power factor angle. The HTS core flux can be found then as per the equation of the flux and the voltage. Following the arcing, residual flux becomes weaker. The residual flux is infected by load features and power storage as well. After maintaining all these factors residual flux will be kept at a steady value. The HTS transformer linked to bus-bar doesn't have any voltage reading of opening phase if the phase is blow out. Due to HTS winding connections and core structure the fluxes will be altered. The flux will attenuate and will reach in a steady value. Finally, the analysed result satisfies the law of Faraday.

The residual flux density is expected reduce after first cycle resulting from losses. It is a damping function of transformer 
losses. The new value of residual flux density, $\mathrm{Br}($ new), is introduced as

$$
B_{r(\text { new })}=B_{r(\text { old })}-\left[B_{m p} \cdot \frac{K_{3} \cdot R}{X_{S}}(2 \cdot(\sin \theta-\theta \cos \theta))\right]
$$

where $K_{3}$ is the correction factor inrush-decay $\mathrm{R}$ is the total resistance of system resistance and transformer winding resistance. The calculations are replicated to analyse the high values of the subsequent cycles. [16]

\section{MitigATING INRUSH CURRENT}

There are two major ways of mitigating inrush current: (i) by finding the best switching time (delay or advance of reclosing time of breaker) and (ii) by controlled switching method. Best switching timing is searched in this section.

\section{A. Inrush current by best switching time}

The simulation result shows the existence of high inrush current produced resulting from saturation of HTS transformer.

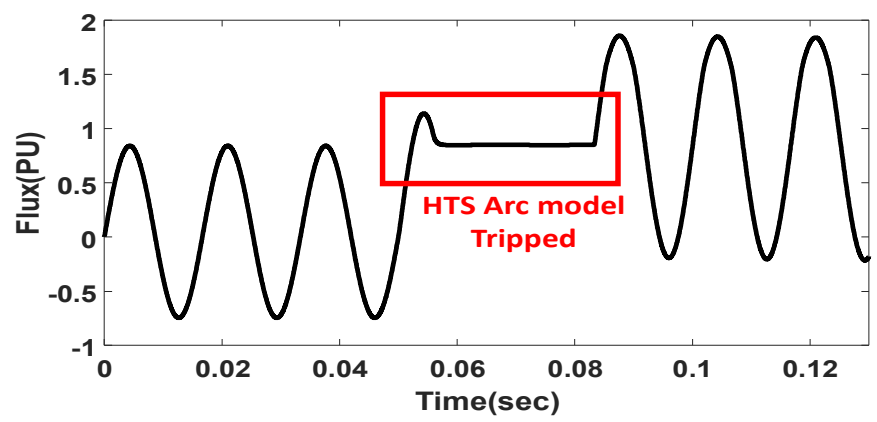

(a)

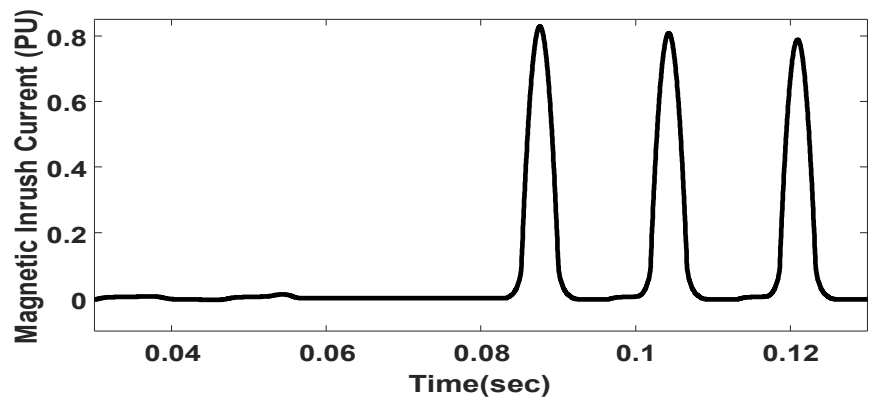

(b)

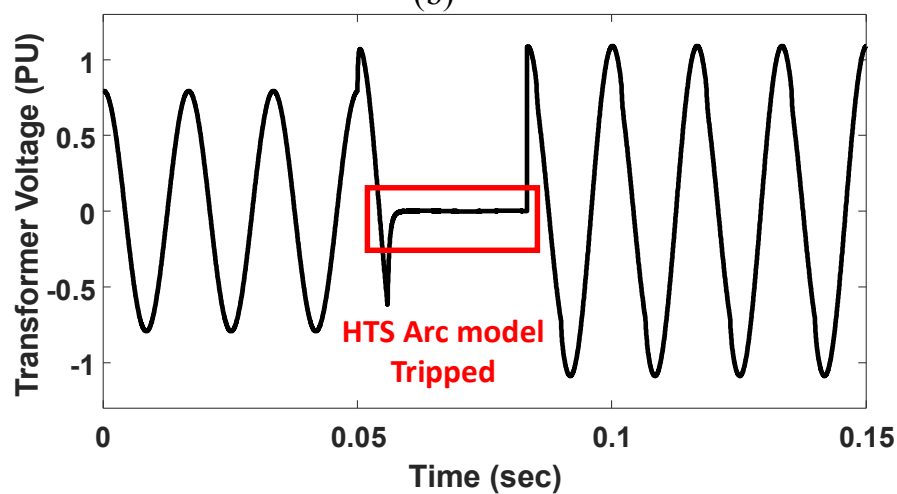

(c)

Figure 6: (a)Flux (PU) (b) Magnetizing current and excitation current (c) Transformer voltage
The HTS breaker arc model in the beginning opens at $\mathrm{t}=3$ cycles $(0.05 \mathrm{sec}$.), then it is recloses at $\mathrm{t}=5$ cycles $(0.09 \mathrm{sec}$. $)$. The high inrush current values with controlled switching of HTS arc model is demonstrated in Figure 6. The inrush current is mitigated in great extent. This feasible method can mitigating the inrush current value to nominal value from six to ten times lower.

\section{B. Calculated values}

There is a significant level of inrush current reduction observed during the simulation. It varies within the range of 11.3 per unit $(\mathrm{pu})$ or closed to $1.8 \mathrm{pu}$ considering different parameters of HTS breaker arc model. The residual fluxes decreases if the operating time of breaker is remarkably steady. However, the inrush current is not likely be reduced lesser than HTS transformer's full load current with the applied method. Although marginal residual fluxes can be obtained with controlled de-energization. The results show the transient varied nearly $11 \%$ from the nominal voltage within time period of 3 cycles. The calculated values are listed in Table I.

TABLE I. CALCULATED VALUES AT Mitigating CONDITION

\begin{tabular}{|c|c|c|c|}
\hline $\begin{array}{c}\text { Energization of HTS transformer } \\
\text { Phase voltage }\end{array}$ & \multicolumn{2}{c|}{$\begin{array}{c}\text { Overvoltage (within permissible } \\
\text { limits) }\end{array}$} \\
\hline $\begin{array}{c}\text { Calculated } \\
\text { minimum value } \\
\text { [p.u] }\end{array}$ & 0.95 & $\begin{array}{c}\text { Phase Voltage } \\
\text { [p.u.] }\end{array}$ & 0.95 \\
\hline $\begin{array}{c}\text { Reference voltage } \\
\text { limit for transient } \\
\text { [p.u.] }\end{array}$ & 0.91 & $\begin{array}{c}\text { Magnetizing flux } \\
\text { [p.u.] }\end{array}$ & 1.98 \\
\hline $\begin{array}{c}\text { Minimum/ } \\
\text { permissible } \\
\text { value [p.u.] }\end{array}$ & 0.93 & $\begin{array}{c}\text { Magnetizing } \\
\text { Current [p.u.] }\end{array}$ & 3.4 \\
\hline $\begin{array}{c}\text { Restoration time } \\
\text { [ms] }\end{array}$ & 45 & $\begin{array}{c}\text { Restoration time } \\
\text { [ms] }\end{array}$ & 45 \\
\hline
\end{tabular}

In Table I, the short-circuit condition highlights the high values for energization of HTS transformer due to mitigated inrush current. The transient results depend on short circuit voltage transient limit which is allowed value of $0.94 \mathrm{pu}$.

\section{1pu permitted inrush current phenomena}

The situation of $1.0 \mathrm{pu}$ inrush current peak permission is investigated for similar scenario in this subsection. The practical specifications for the tolerable deviations is identified for this scenario. The HTS core is led to saturation when transient inrush currents take place. Consequently, magnetic flux reaches its peak following energisation. For this scenario, the method and operating time need to find again.

In Figure 7, magnetic flux result after energization for this scenario is shown. Acceptable tolerances of $1 \mathrm{pu}$ maximum inrush current peak is applied. It is found that the tolerable values vary for positive and negative values of residual flux. It means that the magnetic flux doesn't attain steady state condition for this scenario. The result nonetheless maintains an offset value in the beginning as a result of small damping of the system. If the delay is increased to 7 to 10 cycles, it does not bring significant improvement. The inrush current can still be driven below the full load current ratings of HTS transformer. 
In all cases, the operating time needs to be lessened until desired mitigated result is obtained.

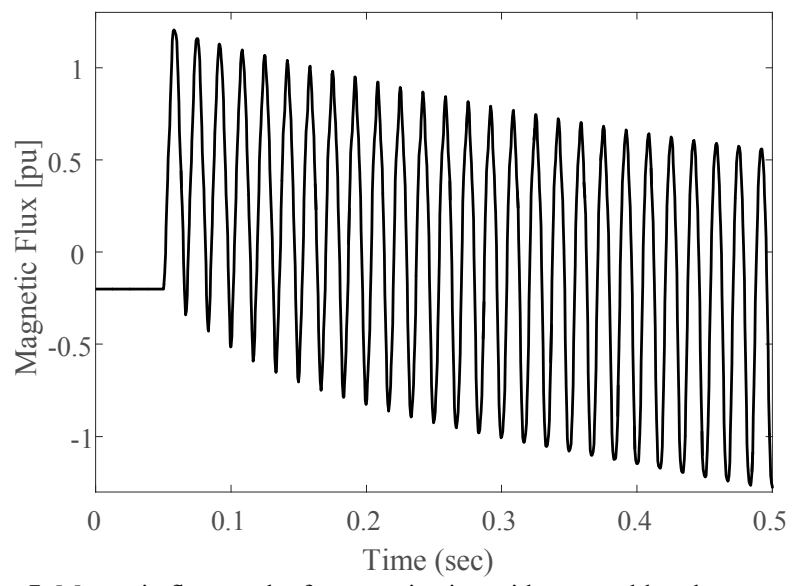

Figure 7: Magnetic flux result after energization with acceptable tolerances of 1 pu maximum inrush current peak

\section{CONCLUSION}

The simulation and calculation studies are carried out for energizing 1 MVA $11 \mathrm{kV} / 415 \mathrm{~V}$ HTS transformers during short circuit condition. Throughout the energizing of the transformers, the HTS breaker arc model is switched off for the time when the voltage crosses the zero point. The situation highlights the increased value of inrush current. Magnetizing flux is straightaway proportional to the value of inrush current. The high inrush current value is observed even after transformer is switched off.

The residual flux mitigation method for HTS transformer is demonstrated in this paper. It can be a realistic means to remove the inrush current as well. The results show the usefulness of the calculation method. It reveals that the calculation can estimate the polarity of the residual flux accurately.

The calculation have some deviation as the breaker model is developed with some realistic assumptions. With the proposed calculation method, inrush currents could be restrained to a lower level along with residual flux. It is found the transient voltage raises to $1.03 \mathrm{pu}$, during HTS transformer's energization. The overvoltage limit hence has vivid impact of inrush current in HTS transformer. The variation of operating time can still be readjusted with future modified HTS breaker arc model.

For future experiments, the arc model with CFI method can be investigated for broad-area systems protection or in SCADA/ EMS central systems.

\section{ACKNOWLEDGMENT}

The authors are grateful for the support to School of Engineering, Computer and Mathematical Sciences, Auckland University of Technology, New Zealand.

\section{REFERENCES}

[1] Stuart C. Wimbush, Large Scale Applications of HTS in New Zealand, Physics Procedia, Pages 221-224, ISSN 1875-3892, Volume 65, 2015.
[2] M. A. Abdul Rahman, T. T. Lie and K. Prasad, "The Effects of Short-Circuit and Inrush Currents on HTS Transformer Windings," in IEEE Transactions on Applied Superconductivity, vol. 22, no. 2, pp. 5500108-5500108, April 2012.

[3] M. A. Abdul Rahman, T. T. Lie and K. Prasad, "Computation of the Thermal Effects of Short Circuit Currents on HTS Transformer Windings," in IEEE Transactions on Applied Superconductivity, vol. 22, no. 6, pp. 55012115501211, Dec. 2012.

[4] M. A. Abdul Rahman, T. T. Lie and K. Prasad, "Performance analysis of HTS transformer with fault current limiting properties on short circuit current," Applied Superconductivity and Electromagnetic Devices (ASEMD), 2011 International Conference on, Sydney, pp. 54-57, NSW, 2011.

[5] C. W. Bumby, A. E. Pantoja, H. J. Sung, Z. Jiang, R. Kulkarni and R. A. Badcock, "Through-Wall Excitation of a Magnet Coil by an External-Rotor HTS Flux Pump," in IEEE Transactions on Applied Superconductivity, vol. 26, no. 4, pp. 1-5, June 2016

[6] Ullah, A., T. T. Lie, K. Gunawardane, and N. K. C. Nair. "Development of browne's arc model for HTS applications." In Power System Technology (POWERCON), 2016 IEEE International Conference on, pp. 1-4. IEEE, 2016.

[7] Ullah, A., T. T. Lie, K. Gunawardane, and N. K. C. Nair. "The improvement of Rate of Rise of Recovery Voltage (RRRV) for an HTS breaker " In 12th IEEE PES Powertech Conference, IEEE, 2017.

[8] Parikh, Urmil, and Bhavesh R. Bhalja. "Mitigation of magnetic inrush current during controlled energization of coupled un-loaded power transformers in presence of residual flux without load side voltage measurements." International Journal of Electrical Power \& Energy Systems 76 (2016): 156-164.

[9] D. Djurek, Z. Medunić, A. Tonejc, and M. Paljević, "PbCO3·2PbO+Ag2O and $\mathrm{PbCO} 3 \cdot \mathrm{PbO}+\mathrm{Ag} 2 \mathrm{O}(\mathrm{PACO})$ systems: route for novel superconductors," Physica C: Superconductivity, vol. 351, p. 4, March 2001.

[10] R. Wesche, High-Temperature Superconductors: Materials, Properties, and Applications. Boston/Dordrecht/London: Kluwer Academic Publishers, 1998.

[11] B. W. McConnell, S. P. Mehta, and M. S. Walker, "HTS transformers," Power Engineering Review, IEEE, vol. 20, pp. 7-11, 2000.

[12] Thomas, Richard P., and Carl-Ejnar Solver. "A Method for Controlled Fault Interruption for Use with HV SF 6 Circuit Breakers." In Power Tech, 2007 IEEE Lausanne, pp. 1135-1140. IEEE, 2007.

[13] Ebner, A. "Determination of acceptable closing time scatter and residual flux measurement uncertainty for controlled switching of transformers." In Proceedings of the 16th international symposium on high voltage engineering, pp. 1-6. 2009.

[14] Controlled switching Of HVAC circuit breakers: guide for application lines, reactors, capacitors, transformers: Part-I. ELECTRA 183, Cigré Working Group A3.07; April 1999. p. 43-73.

[15] Controlled switching Of HVAC circuit breakers: planning, specification and testing of controlled switching systems. ELECTRA 197. Cigré Working Group A3.07; August 2001. p. 22-33.

[16] Controlled switching Of HVAC circuit breakers: guide for application lines, reactors, capacitors, transformers: Part-II. ELECTRA 185. Cigré Working Group A3.07; August 1999. p. 37-57.

[17] Kulkarni, Shrikrishna V., and S. A. Khaparde. Transformer engineering: design and practice. Vol. 25. CRC Press, 2004.

[18] M. Young, The Technical Writer's Handbook. Mill Valley, CA: University Science, 1989

[19] Lotfi, Abbass. "Identification of KEMA arc model parameters in high voltage circuit breaker by using of genetic algorithm." In Power and Energy Conference, 2008. PECon 2008. IEEE 2nd International, pp. 1515-1517. IEEE, 2008.

[20] Orama-Exclusa, Lionel R., and Bienvenido Rodríguez-Medina. "Numerical arc model parameter extraction for SF6 circuit breaker simulations." In Proc. International Power System Transients Conference (IPST). 2003.

[21] Samet, H., Golshan, M.E.H.: 'Employing stochastic models for prediction of arc furnace reactive power to improve compensator performance', IET Gener. Transm. Distrib., 2008, 2, (4), pp. 505-515

[22] Samet, H., Mojallal, A.: 'Enhancement of electric arc furnace reactive power compensation using Grey-Markov prediction method', IET Gener. Transm. Distrib., 2014, 8, (9), pp. 1626-1636.

[23] Samet, Haidar, and Aslan Mojallal. "Enhancement of electric arc furnace reactive power compensation using Grey-Markov prediction method." IET generation, transmission \& distribution 8, no. 9 (2014): 1626-1636.

[24] Bahirat, Himanshu, Muhammad Ali, and K. K. Praveen. "Effects of Transient Recovery Voltages on Circuit Breaker Ratings." Instructor (2008). 